\title{
Evaporation of Silver during Cofiring with Barium Titanate
}

\author{
Chin-Yi Chen and Wei-Hsing Tuan* \\ Institute of Materials Science and Engineering, National Taiwan University, Taipei, Taiwan 106, Republic of China
}

\begin{abstract}
Silver and Ag-Pd alloy are cofired with $\mathrm{BaTiO}_{3}$-based dielectrics during the manufacturing of capacitors. The diffusion of silver into $\mathrm{BaTiO}_{3}$ during sintering is very slow. However, the vapor pressure of silver is high at temperatures greater than the melting point of silver $\left(960^{\circ} \mathrm{C}\right)$. The effect of the evaporation of silver during the sintering with $\mathrm{BaTiO}_{3}$ at $1200^{\circ}, \mathbf{1 2 5 0}^{\circ}$, and $1290^{\circ} \mathrm{C}$ is investigated in the present study. The silver vapor can transport through the pore channel of the dielectrics to a distance of a few hundred micrometers. The melting point of Ag-Pd alloy is higher than that of silver; therefore, the transportation of silver vapor from Ag-Pd alloy is hardly observed at temperatures $>1200^{\circ} \mathrm{C}$.
\end{abstract}

\section{Introduction}

SILVER and silver-palladium alloys are widely used as electrode material in capacitors, because of their oxidation resistance at high temperature and their compatibility with dielectrics. In a multilayer structure, the silver-containing electrodes are cofired with dielectrics. During the cofiring, silver diffusion into the dielectrics is expected to be negligible, despite the fact that information regarding the diffusion of silver in dielectrics is not available. Therefore, multilayer structures with dielectric layers 5-20 $\mu \mathrm{m}$ thick between the silver-containing electrodes are developed, to enhance the capacitance:volume ratio. The thickness of the dielectric layer even may be reduced to $2 \mu \mathrm{m}$ in the next five years. Such a multilayer structure can be realized on an industrial scale, based, at least in part, on the fact that the diffusion of silver in a dielectric during sintering is extremely slow.

However, silver can migrate over a distance that is on the scale of tens of micrometers, under conditions of a humid environment and applied dc field at low temperature. ${ }^{1}$ The electrochemical migration of silver can be significantly reduced by alloying silver with palladium. ${ }^{2}$

In the present study, we demonstrate that, apart from the diffusion at high temperature and electrochemical migration at low temperature, mass transportation of silver also can occur via the evaporation of silver at high temperature. The silver vapor can travel a distance of a few hundred micrometers. We also demonstrate that the evaporation of silver can be suppressed by adding palladium to silver.

\section{Experimental Procedure}

To investigate the evaporation of silver during cofiring with $\mathrm{BaTiO}_{3}$, an inner specimen that contains silver or Ag-Pd alloy has been embedded into a $\mathrm{BaTiO}_{3}$ powder compact, as shown in Fig. 1. Three different combinations have been used: $\mathrm{a}\left(\mathrm{BaTiO}_{3}+10\right.$

W. Huebner-contributing editor

Manuscript No. 189169. Received August 9, 1999; approved December 28, 1999. Supported by the National Science Council, Republic of China, through Contract No. NSC85-2216-E002-024.

${ }^{\star}$ Member, American Ceramic Society. wt\% Ag) powder compact in $\mathrm{BaTiO}_{3}$ powder, a sintered $\left(\mathrm{BaTiO}_{3}\right.$ $+10 \mathrm{wt} \% \mathrm{Ag})$ specimen in $\mathrm{BaTiO}_{3}$ powder, and a $\left(\mathrm{BaTiO}_{3}+\right.$ $14.3 \mathrm{wt} \% 70 \mathrm{Ag} / 30 \mathrm{Pd}$ ) powder compact in $\mathrm{BaTiO}_{3}$ powder. The preparation procedures are described as follows.

\section{(1) $\left(\mathrm{BaTiO}_{3}+10\right.$ wt\% Ag) Powder Compact in $\mathrm{BaTiO}_{3}$}

Detailed experimental procedures for the $\mathrm{BaTiO}_{3}+\mathrm{Ag}$ powder mixture can be found in a previous study. ${ }^{3} \mathrm{~A}$ brief description of the procedures is given here. $\mathrm{BaTiO}_{3}$ powder (No. 219-6, Ba:Ti ratio of 0.995; Ferro Co., Cleveland, $\mathrm{OH}$ ) and silver nitrate (Johnson Matthey Chemicals Co., Ward Hill, MA) were ballmilled together in deionized water for $4 \mathrm{~h}$. The grinding media used were zirconia balls. The slurry was stirred and dried slowly to remove the water. Then, the powder mixtures were calcined at $300^{\circ} \mathrm{C}$ for $3 \mathrm{~h}$ in air to decompose the $\mathrm{AgNO}_{3}$, to result in a silver content of $10 \mathrm{wt} \%$ in $\mathrm{BaTiO}_{3}$. Then, the dried lumps were crushed and passed through a plastic sieve with an aperture size of $100 \mu \mathrm{m}$. The powder compacts, with a diameter of $1 \mathrm{~cm}$, were prepared by pressing uniaxially at $20 \mathrm{MPa}$. Then, the compact was buried in the $\mathrm{BaTiO}_{3}$ powder and pressed in a steel die (1 in. in diameter) at a pressure of $25 \mathrm{MPa}$.

\section{(2) Sintered $\left(\mathrm{BaTiO}_{3}+10 w t \%\right.$ Ag) Specimen in $\mathrm{BaTiO}_{3}$}

The $\left(\mathrm{BaTiO}_{3}+10 \mathrm{wt} \% \mathrm{Ag}\right)$ powder compacts that were prepared using the procedures described in the last section first were sintered at $1290^{\circ} \mathrm{C}$ for $2 \mathrm{~h}$. The relative density of the sintered specimens was $92 \%$. Then, the sintered $\left(\mathrm{BaTiO}_{3}+10 \mathrm{wt} \% \mathrm{Ag}\right)$ specimen was buried in the $\mathrm{BaTiO}_{3}$ powder and pressed into a disk 1 in. in diameter.

\section{(3) $\left(\mathrm{BaTiO}_{3}+14.3 w t \% 70 \mathrm{Ag} / 30 \mathrm{Pd}\right)$ Powder Compact in $\mathrm{BaTiO}_{3}$}

$\mathrm{BaTiO}_{3}$ powder and 70Ag/30Pd powder (No. PD-630A, Shoei Chemicals, Inc., Tokyo, Japan) were ball-milled in deionized water for $4 \mathrm{~h}$. The resulting amount of silver in the $\mathrm{BaTiO}_{3}+$ $70 \mathrm{Ag} / 30 \mathrm{Pd}$ powder mixture was $10 \mathrm{wt} \%$. Then, the $\left(\mathrm{BaTiO}_{3}+\right.$ $14.3 \mathrm{wt} \% 70 \mathrm{Ag} / 30 \mathrm{Pd}$ ) powder compact with a diameter of $1 \mathrm{~cm}$ was embedded in $\mathrm{BaTiO}_{3}$ powder to form a compact 1 in. in diameter.

The composites were sintered in a covered alumina crucible at $1200^{\circ}, 1250^{\circ}$, and $1290^{\circ} \mathrm{C}$ for $2 \mathrm{~h}$ in air. The heating and cooling rates were $3^{\circ} \mathrm{C} / \mathrm{min}$. Several monolithic $\mathrm{BaTiO}_{3}$ specimens also were prepared, using the same procedures. A separate sintering study was conducted using a differential dilatometer (Theta Industries, Port Washington, NY). Two runs were conducted to check

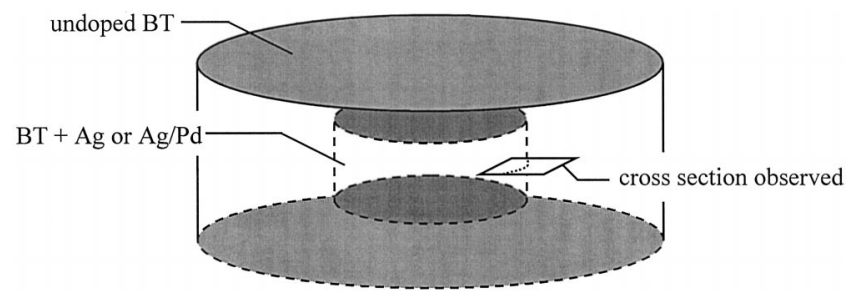

Fig. 1. Design of the embedded specimens; a small silver- or $\mathrm{Ag} / \mathrm{Pd}-$ containing pellet is embedded in a $\mathrm{BaTiO}_{3}$ disk. 

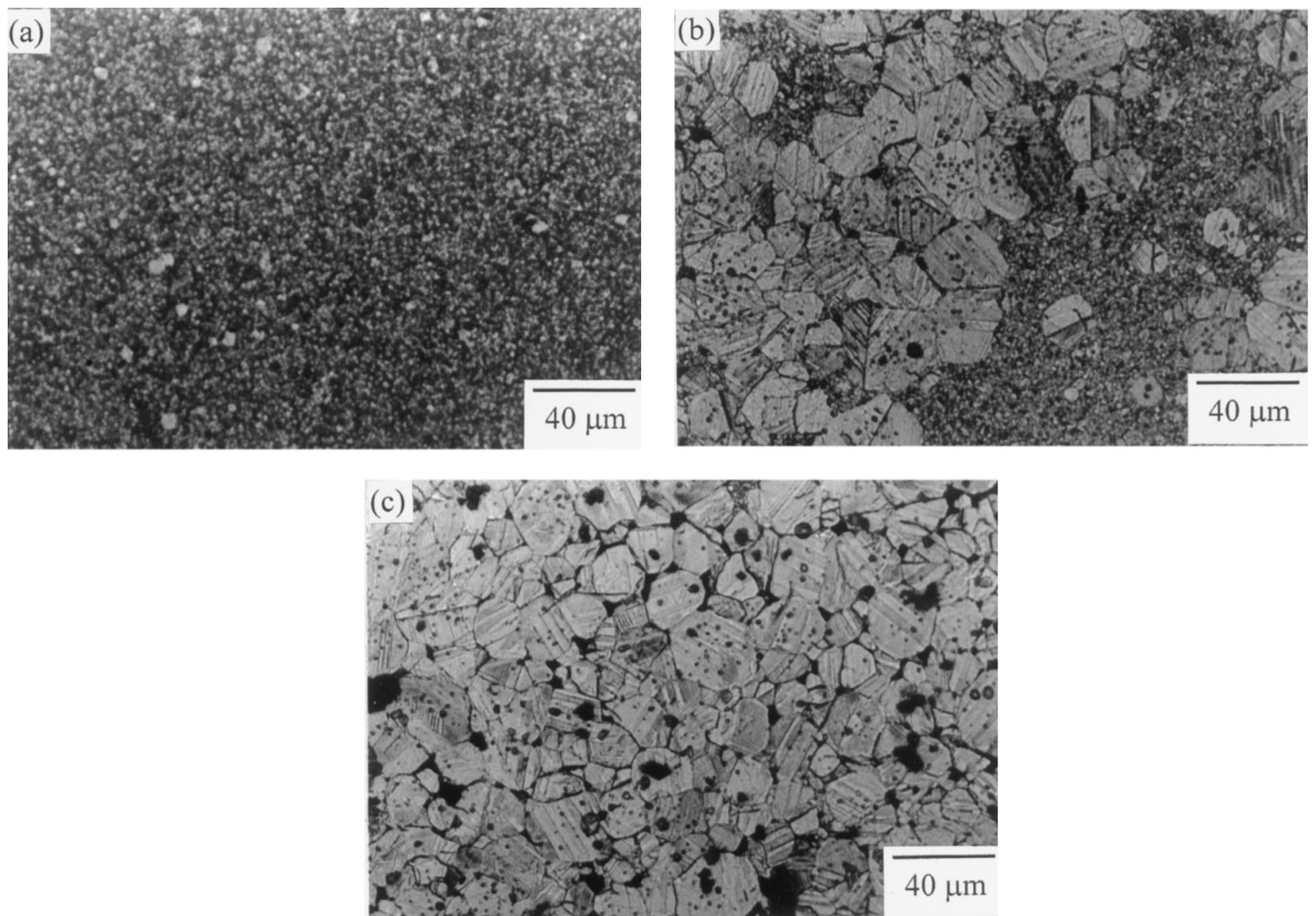

Fig. 2. Microstructures of the monolithic $\mathrm{BaTiO}_{3}$ specimens sintered at (a) $1200^{\circ}$, (b) $1250^{\circ}$, and (c) $1290^{\circ} \mathrm{C}$ for $2 \mathrm{~h}$.
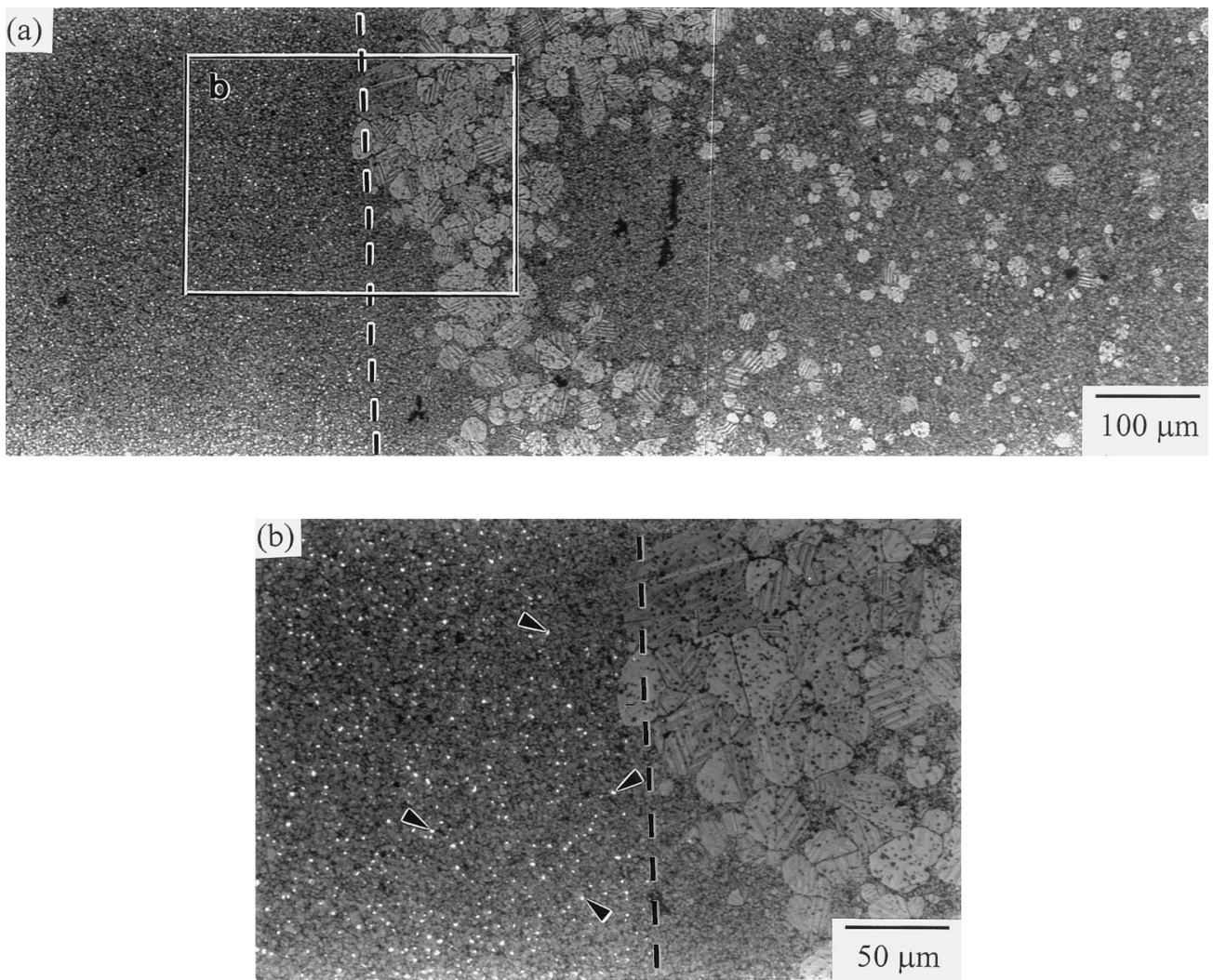

Fig. 3. (a) Microstructure of the $\left(\mathrm{BaTiO}_{3}+10 \mathrm{wt} \% \mathrm{Ag}\right)$ powder compact in $\mathrm{BaTiO}_{3}$ specimen sintered at $1200^{\circ} \mathrm{C}$ for $2 \mathrm{~h}$; an enlarged view of the noted area in Fig. 3(a) is shown in Fig. 3(b). Some silver inclusions are indicated with arrows. Dotted line indicates the original interface, and the inner portion is located at the left-hand side of the interface. 
the reproducibility of the sintering kinetics data. The polished surface was prepared by grinding with $\mathrm{SiC}$ particles and polishing with $\mathrm{Al}_{2} \mathrm{O}_{3}$ particles. The grain boundaries and domain structure were revealed by etching with a solution of $\mathrm{HCl}$ and $\mathrm{HF}^{4}$ The solution was dilute enough to leave the silver inclusions intact. The microstructure was observed using optical microscopy.

\section{Results}

Figure 2 shows the microstructures of the monolithic $\mathrm{BaTiO}_{3}$ specimens sintered at $1200^{\circ}, 1250^{\circ}$, and $1290^{\circ} \mathrm{C}$ for $2 \mathrm{~h}$. A very small amount of abnormal grains is observed in the specimen that was sintered at $1200^{\circ} \mathrm{C}$. However, most of the grains in the specimen that was sintered at $1290^{\circ} \mathrm{C}$ are abnormal grains.

\section{(1) (BaTiO $_{3}+10 w t \%$ Ag) Powder Compact in $\mathrm{BaTiO}_{3}$}

Figures 3, 4, and 5 show the microstructures of the embedded specimens that were sintered at $1200^{\circ}, 1250^{\circ}$, and $1290^{\circ} \mathrm{C}$, respectively. The inner specimen was formed first, then diepressed within $\mathrm{BaTiO}_{3}$ powder. Because of the constraint applied by the steel die, the inner portion was not joined together well with the external part in the lateral direction during the die compaction.
Flaws, such as relatively large pores, are formed at the interface after sintering. However, the presence of flaws allows us to locate the original interface between the inner and external regions after sintering. The original interface in Figs. $3-5$ is indicated with a dotted line. For the specimen that was sintered at $1200^{\circ} \mathrm{C}$ (Fig. 3), the $\mathrm{BaTiO}_{3}$ grains in the inner region are small. A silver depletion region is observed inside the original interface, which indicates the evaporation of silver. A region with only $\mathrm{BaTiO}_{3}$ abnormal grains is located just outside the original interface. Then, a small amount of abnormal grains are found in the far end of the external region. The presence of a small amount of silver can promote the formation of abnormal grains. ${ }^{3}$ Therefore, the presence of the abnormal grain region indicates the transportation of silver vapor. The transport distance for the silver vapor is in the range of 100-300 $\mu \mathrm{m}$.

For the specimen that was sintered at $1250^{\circ} \mathrm{C}$ (see Fig. 4), a region with only abnormal $\mathrm{BaTiO}_{3}$ grains is located just outside the original interface. Silver inclusions are observed in the abnormal grain region (see Figs. 4(b) and (c)). The silver inclusions can be found $\sim 700 \mu \mathrm{m}$ from the original interface. For the specimen that was sintered at $1290^{\circ} \mathrm{C}$, a region with only abnormal grains also is observed outside of the original interface (see Fig. 5). Silver inclusions are found $\sim 800 \mu \mathrm{m}$ from the original interface.
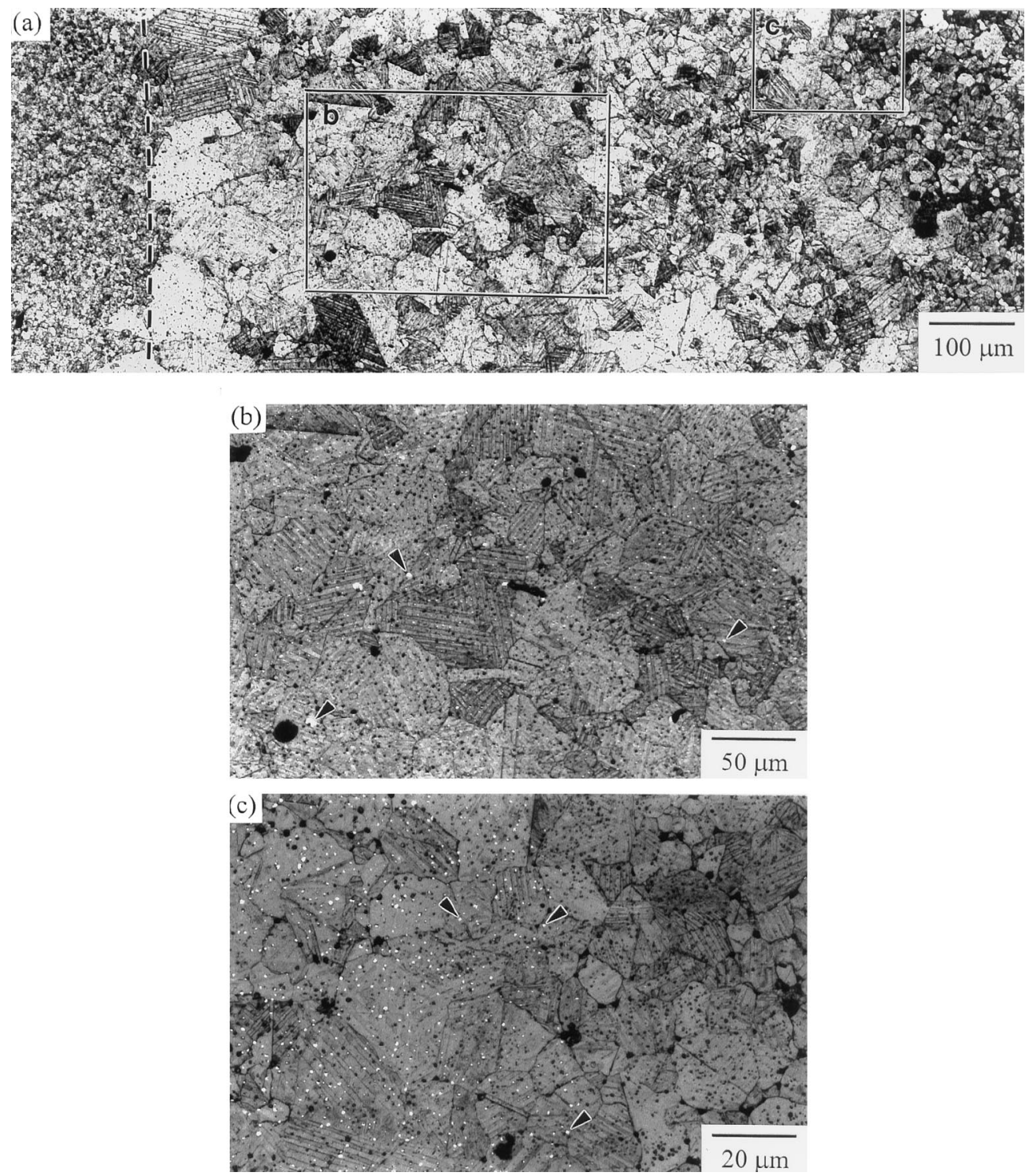

Fig. 4. (a) Microstructure of the $\left(\mathrm{BaTiO}_{3}+10 \mathrm{wt} \% \mathrm{Ag}\right)$ powder compact in $\mathrm{BaTiO}_{3}$ specimen sintered at $1250^{\circ} \mathrm{C}$ for $2 \mathrm{~h}$; enlarged views of the noted areas in Fig. 4(a) are shown in Figs. 4(b) and (c). Some silver inclusions are indicated with arrows. Dotted line indicates the original interface, and the inner portion is located at the left-hand side of the interface. 


\section{(2) Sintered $\left(\mathrm{BaTiO}_{3}+10 \mathrm{wt} \% \mathrm{Ag}\right)$ Specimen in $\mathrm{BaTiO}_{3}$}

The microstructure of the embedded specimen that contained the sintered $\left(\mathrm{BaTiO}_{3}+10 \mathrm{wt} \% \mathrm{Ag}\right)$ inner specimen is shown in Fig. 6. The specimen was sintered at $1290^{\circ} \mathrm{C}$ for $2 \mathrm{~h}$. A line of large holes can be treated as the markers of the original interface. No silver inclusions are found in the external region. For the specimens that were sintered at $1200^{\circ}$ and $1250^{\circ} \mathrm{C}$, no silver inclusions are found in the external region.

\section{(3) $\left(\mathrm{BaTiO}_{3}+14.3 w t \% 70 \mathrm{Ag} / 30 \mathrm{Pd}\right)$ Powder Compact in $\mathrm{BaTiO}_{3}$}

The microstructures of the embedded specimens that were sintered at $1200^{\circ}, 1250^{\circ}$, and $1290^{\circ} \mathrm{C}$ are shown in Fig. 7. No silver inclusions are found in the external region.

\section{Discussion}

Recent study by the current authors ${ }^{3}$ indicated that the presence of silver inclusions has little effect on the densification behavior of $\mathrm{BaTiO}_{3}$. However, a small amount $(\sim 0.3 \mathrm{wt} \%)$ of silver inclusions can increase both the size and amount of abnormal grains significantly. The amount of silver is greater than $\sim 0.3 \mathrm{wt} \%$; thus, the grain growth of $\mathrm{BaTiO}_{3}$ is prohibited because the diffusion distance between the $\mathrm{BaTiO}_{3}$ grains is increased due to the presence of silver inclusions. Thus, the size of $\mathrm{BaTiO}_{3}$ grains in the inner region of the specimens that contain $10 \mathrm{wt} \%$ silver is small. The external region contains no silver inclusions in the beginning. No silver is found in the far end of the external specimen after sintering; furthermore, the microstructures at the far end of the external region are similar to those of the monolithic specimens shown in Fig. 2. However, abnormal grains and silver inclusions are found in the external $\mathrm{BaTiO}_{3}$ region next to the original interface as the $\left(\mathrm{BaTiO}_{3}+\mathrm{Ag}\right)$ powder compacts are embedded in $\mathrm{BaTiO}_{3}$ (see Figs. 3-5). This abnormal grain region is composed of $100 \%$ abnormal grains; furthermore, the size of the abnormal grains is significantly larger than that of the abnormal grains in the far end of the external region.

Silver can evaporate at a temperature above its melting point, which is $960^{\circ} \mathrm{C}$. The vapor pressure $(P)$ of silver above its melting point is a function of temperature $T:{ }^{5}$
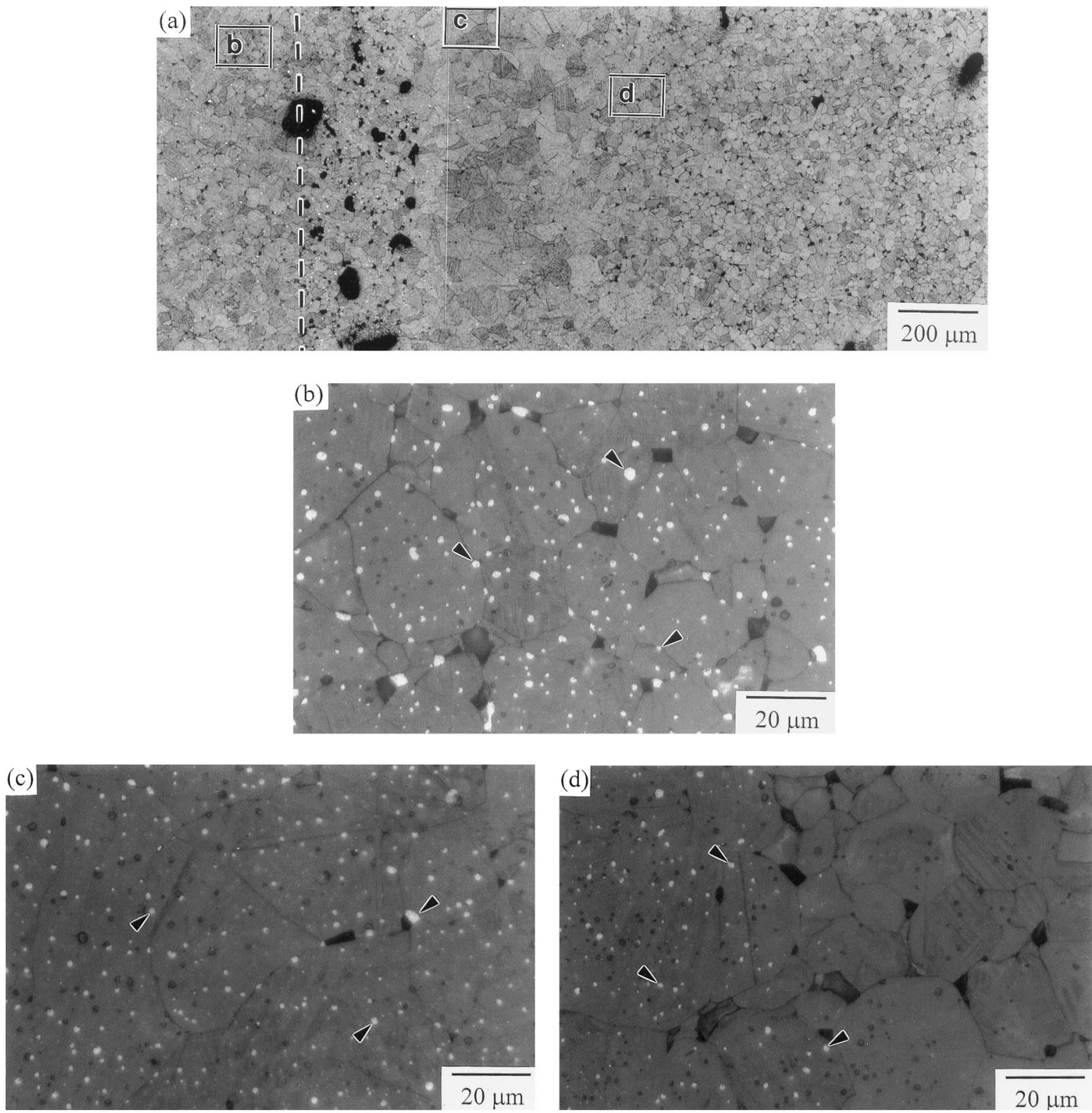

Fig. 5. (a) Microstructure of the $\left(\mathrm{BaTiO}_{3}+10 \mathrm{wt} \% \mathrm{Ag}\right)$ powder compact in $\mathrm{BaTiO}_{3}$ specimen sintered at $1290^{\circ} \mathrm{C}$ for $2 \mathrm{~h}$; enlarged views of the noted areas in Fig. 5(a) are shown in Figs. 5(b), (c), and (d). Some silver inclusions are indicated with arrows. Dotted line indicates the original interface, and the inner portion is located at the left-hand side of the interface. 

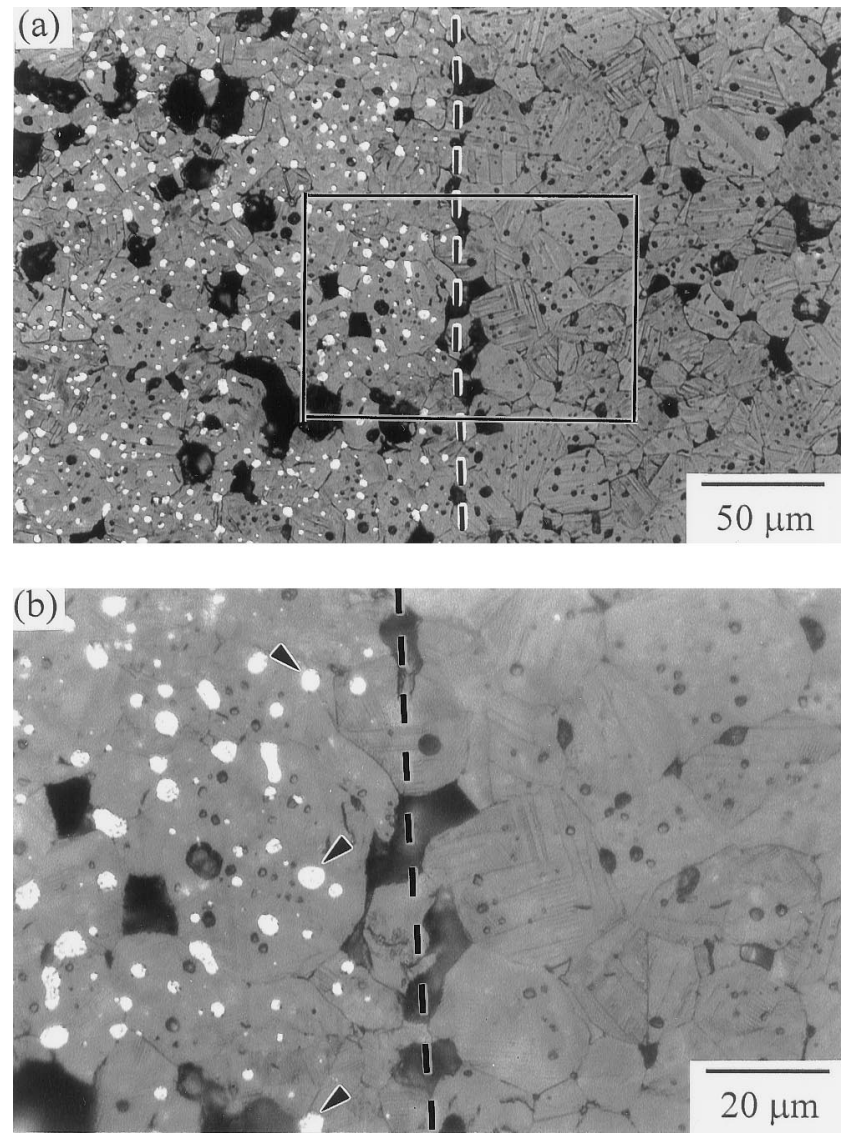

Fig. 6. (a) Microstructure of the sintered $\left(\mathrm{BaTiO}_{3}+10 \mathrm{wt} \% \mathrm{Ag}\right)$ disk in $\mathrm{BaTiO}_{3}$ specimen sintered at $1290^{\circ} \mathrm{C}$ for $2 \mathrm{~h}$; an enlarged view of the noted area in Fig. 6(a) is shown in Fig. 6(b). Some silver inclusions are indicated with arrows. Dotted line indicates the original interface, and the inner portion is located at the left-hand side of the interface.

$$
\ln P=-\frac{33200}{T}-0.85 \ln T+20.31
$$

The vapor pressure of silver at $1200^{\circ}, 1250^{\circ}$, and $1290^{\circ} \mathrm{C}$ is 0.00022 , 0.00044 , and $0.00076 \mathrm{~atm}$, respectively. Thus, the silver inclusions are found $\sim 200,700$, and $800 \mu \mathrm{m}$ away from the original interface as the $\left(\mathrm{BaTiO}_{3}+10\right.$ wt\% Ag) powder compacts are sintered in $\mathrm{BaTiO}_{3}$ specimens at $1200^{\circ}, 1250^{\circ}$, and $1290^{\circ} \mathrm{C}$, respectively.

The sintering kinetics of monolithic $\mathrm{BaTiO}_{3}$ powder compact are shown in Fig. 8. The compact starts to densify at a temperature of $\sim 1100^{\circ} \mathrm{C}$. The heating rate is a constant; therefore, the densification rate is estimated by differentiating the relative density, with regard to temperature. The densification attains its highest rate at a temperature of $\sim 1220^{\circ} \mathrm{C}$. The silver starts to generate vapor at $>960^{\circ} \mathrm{C}$, and the density of the external region is still low at that temperature. Thus, the vapor can be transported through the pore channels in the external region during sintering. The relative density of $\mathrm{BaTiO}_{3}$ after sintering at $1200^{\circ} \mathrm{C}$ for $2 \mathrm{~h}$ is only $70 \%$. Most pore channels remained open throughout the entire sintering stage. The silver vapor can transport along the pore channel, despite the fact that the silver vapor pressure is relatively low at $1200^{\circ} \mathrm{C}$. The pore channel is sealed off as the density of the external region increases to $>90 \%$; then, the silver vapor is deposited and condensed into a silver melt on the surface of the pores. The silver vapor does not reach the far end of the external region; thus, the population of silver inclusions decreases sharply at a distance of a few hundred micrometers.

The formation of abnormal $\mathrm{BaTiO}_{3}$ grains originates from the density heterogeneity. ${ }^{4,6}$ The presence of the silver melt facilitates the rearrangement of $\mathrm{BaTiO}_{3}$ particles: the density heterogeneities
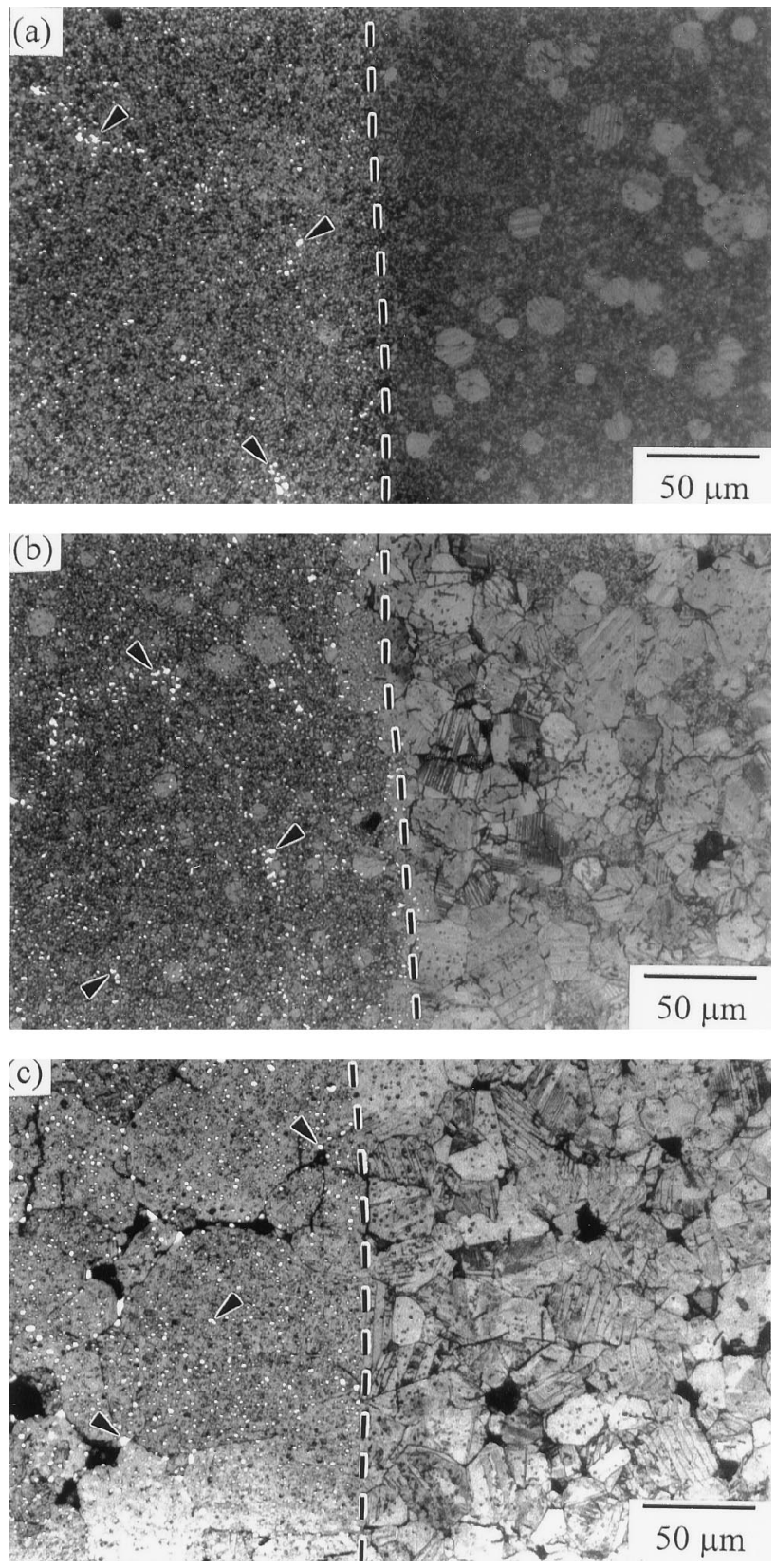

Fig. 7. Microstructure of the $\left(\mathrm{BaTiO}_{3}+14.3 \mathrm{wt} \% 70 \mathrm{Ag} / 30 \mathrm{Pd}\right)$ powder compact in $\mathrm{BaTiO}_{3}$ specimen sintered at (a) $1200^{\circ}$, (b) $1250^{\circ}$, and (c) $1290^{\circ} \mathrm{C}$ for $2 \mathrm{~h}$. Some $\mathrm{Ag} / \mathrm{Pd}$ inclusions are indicated with arrows. Dotted line indicates the original interface, and the inner portion is located at the left-hand side of the interface.

are thus formed in the presence of a silver melt. ${ }^{7}$ The density heterogeneities act as nuclei for the abnormal grains; thus, abnormal grains are formed in the region with evaporated silver inclusions. Therefore, a region with only abnormal grains is observed in the external region.

The $\left(\mathrm{BaTiO}_{3}+10 \mathrm{wt} \% \mathrm{Ag}\right)$ powder compact is sintered first and then inserted into the $\mathrm{BaTiO}_{3}$ powder compact; therefore, no silver inclusions are found in the external region (Fig. 6). The silver inclusions are surrounded by $\mathrm{BaTiO}_{3}$ grains in the inner specimen; therefore, the evaporation of silver can occur only on the exterior surface of the inner specimen. The amount of silver that can be vaporized is small; therefore, no silver inclusions are observed in the external region. Furthermore, the results also imply that the diffusion of silver in the $\mathrm{BaTiO}_{3}$ grains is slow.

The melting point of $70 \mathrm{Ag} / 30 \mathrm{Pd}$ is $1175^{\circ} \mathrm{C},{ }^{8}$ which is much higher than that of silver. Thus, the vapor pressure of silver can be reduced significantly. Therefore, no silver inclusions are found in 


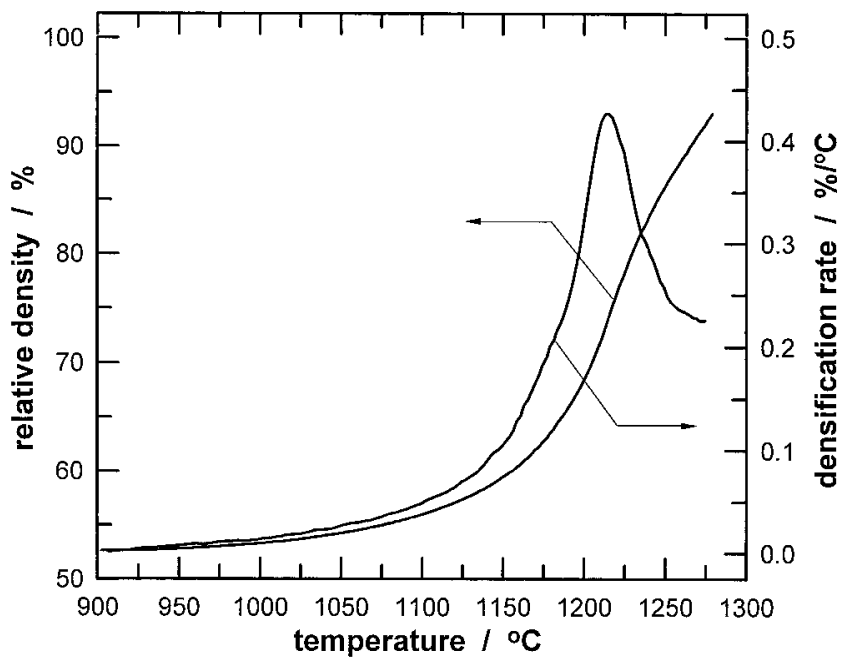

Fig. 8. Sintering kinetics of monolithic $\mathrm{BaTiO}_{3}$, as a function of temperature.

the external region of the $\left(\mathrm{BaTiO}_{3}+14.3 \mathrm{wt} \% \mathrm{Ag} / \mathrm{Pd}\right)$ in the $\mathrm{BaTiO}_{3}$ specimens (Fig. 7).

\section{Conclusions}

The present study demonstrates that silver can evaporate at high temperature. The silver vapor can travel a distance of a few hundred micrometers through the pore channels in a dielectric during cofiring. The presence of silver vapor can promote the formation of abnormal grains. The existence of silver inclusions in the dielectric may reduce the insulation resistance and breakdown voltage. Thus, silver transportation through its evaporation should be avoided. The transportation of silver vapor can be reduced either by surrounding silver inclusions with dense $\mathrm{BaTiO}_{3}$ grains or by using Ag-Pd alloy instead.

\section{References}

${ }^{1}$ H. C. Ling and A. M. Jackson, "Correlation of Silver Migration with Temperature-Humidity-Bias (THB) Failure in Multilayer Ceramic Capacitors," IEEE Trans. Compon., Hybrids, Manuf. Technol., CHMT-12 [1] 130-37 (1989).

${ }^{2}$ J. C. Lin and J. Y. Chan, "On the Resistance of Silver Migration in Ag-Pd Conductive Thick Films under Humid Environment and Applied d.c. Field," Mater. Chem. Phys., 43 [2] 256-65 (1996).

${ }^{3}$ C.-Y. Chen and W.-H. Tuan, "Effect of Silver on the Sintering and Grain-Growth Behavior of $\mathrm{BaTiO}_{3}, "$ J. Am. Ceram. Soc., in review.

${ }^{4}$ F. Kulcsar, "A Microstructure Study of Barium Titanate Ceramics," J. Am. Ceram. Soc., 39 [1] 13-17 (1956).

${ }^{5}$ D. R. Gaskell, Introduction of Metallurgical Thermodynamics, 2nd Ed.; p. 589. Hemisphere Co., New York, 1981.

${ }^{6}$ D. Kolar, "Discontinuous Grain Growth in Multiphase Ceramics"; pp. 529-45 in Ceramic Transactions, Vol. 7, Sintering of Advanced Ceramics. Edited by C. A. Handwerker, J. E. Blendell, and W. A. Kaysser. American Ceramic Society, Westerville, OH, 1990

${ }^{7}$ J.-M. Heintz, M. Sanz, E. Marquestaut, J. Etourneau, and J.-P. Bonnet, "Influence of $\mathrm{BaCuO}_{2}$ on the Sintering and Properties of $\mathrm{YBa}_{2} \mathrm{Cu}_{3} \mathrm{O}_{7-x}$-Based Ceramics," J. Am. Ceram. Soc., 74 [5] 998-1002 (1991).

${ }^{8}$ S. F. Wang, J. P. Dougherty, W. Huebner, and J. G. Pepin, "Silver-Palladium Thick-Film Conductors," J. Am. Ceram. Soc., 77 [12] 3051-72 (1994). 